\title{
Opinion of undergraduate medical students of North Karnataka on case based learning for teaching Medical Microbiology
}

\author{
Sudheendra Kulkarni, ${ }^{* 1}$ Chandrakant Chillarge, ${ }^{2}$ Kumar Sai Sailesh $^{3}$ \\ ${ }^{1}$ Tutor \& Nodal Officer for IDSP, Department of Microbiology, Bidar Institute of Medical Sciences, Bidar, Karnataka, India. \\ ${ }^{2}$ Professor \& HOD, Department of Microbiology, Bidar Institute of Medical Sciences, Bidar, Karnataka, India. \\ ${ }^{3}$ Assistant Professor, Department of Physiology, Little Flower Institute of Medical Sciences and Research, Angamaly, Kerala, India.
}

\section{Abstract}

The present study was undertaken to observe the student's opinion regarding the case based learning for teaching medical microbiology. The study was conducted in the Department of Microbiology, Bidar Institute of Medical sciences, Bidar, North Karnataka. 100 second, year MBBS students were included in the study. Students were exposed to case based lecture (topic-H.Pylori). After the Case based learning (CBL), the opinion of students was taken by using self administered questionnaire with 5 point likert scale. In the present study most of the student's preferred case based learning. We recommend including CBL as a part and parcel of medical microbiology curriculum for better understanding of subject and for practical applications.

Keywords: Case based learning, Medical students, Medical Microbiology.

\section{INTRODUCTION}

Didactic lecture (DL) is the most common teaching method used in India to teach Medical students. It totally depends on teaching skill of the teacher and sometimes may fail to motivate all students as it may not involve the students actively. [1] Case-based learning (CBL) is a long established pedagogical method, which is defined in a number of ways depending on the discipline and type of 'case' employed. [2] In contrast Case based learning makes the student to involve actively and helps to improve learning skills of student. [3] In case based learning students will be divided into groups and cases will be presented to them which they should solve with discussing with their group. Here role of teacher is only to coordinate and facilitate only. However to implement this system to large size class room may be difficult as we need more teachers. [4]

In medicine, Microbiology has its own importance as the student learn here about different types of microbes and their effects on body so that in future he can correlate the signs and symptoms of the disease with the type of microbe and can offer effective treatment. So it is very essential to train students from undergraduate level by using case based learning.

The present study was undertaken to observe the student's opinion regarding the case based learning for teaching medical microbiology.

\section{MATERIALS AND METHODS}

The study was approved by Institutional Ethics Committee. A written, informed consent was obtained from all the participants. The study was performed in accordance with the "Ethical Guidelines for Biomedical Research on Human Participants, 2006" by the Indian Council of Medical Research and the Declaration of Helsinki, 2008.

\section{Study Design}

The present study was a cross-sectional study

Participants, Inclusion and exclusion criteria

\author{
Address for correspondence* \\ Sudheendra Kulkarni \\ Tutor \& Nodal Officer for IDSP, Department of Microbiology, \\ Bidar Institute of Medical Sciences, \\ Bidar, Karnataka, India.
}

The study was conducted in the Department of Microbiology, Bidar Institute of Medical sciences, Bidar. 100 second year MBBS students were included in this study. The study was approved by institutional ethical committee and free, voluntary, written informed consent was taken from all the students prior to the study. Students who are regular to the classes and willing were included in the study.

\section{Inclusion criteria}

Students of both sex and age group between 18-24.

Willing students

\section{Exclusion criteria}

Unwilling students.

Students were exposed to case based lecture (topicH.Pylori) comprising presentation of the case for 10 minutes and faculty and student interaction to explain the case for 5 minutes followed by teaching basic microbiology related to case for 30 minutes and discussion to resolve case for 10 minutes. After the CBL the opinion of students were taken by using self administered questionnaire with 5 point likert scale.[4] 5=Strongly agree;4=Agree;3=neutral; 2=Disagree;1=Strongly disagree

\section{Data analysis}

Data was analyzed by using 20.0. Values are expressed in percentages.

\section{RESULTS}

Results were presented in table no 1 . In the present study most of the students preferred case based learning.

\section{DISCUSSION}

Case based learning is a new approach to teach medical sciences effectively. [5] It was reported that students enjoy CBL and think that it enhances their learning. Teachers enjoy CBL, partly because it engages, and is perceived to motivate, students.[2] previous studies reported that Significantly better acadenic performance was observed after didactic teaching. However, the students' feedback indicated that case-based teaching could be used as an alternative to lectures and may facilitate skills acquisition, which is considered to be important in professional problem-solving during nursing care.[5] Praveen R 
Table :1 Students opinion regarding the case based learning for teaching medical microbiology.

\begin{tabular}{|l|l|l|l|l|l|l|}
\hline Sno & Items & $\mathbf{5}$ & $\mathbf{4}$ & $\mathbf{3}$ & $\mathbf{2}$ & $\mathbf{1}$ \\
\hline 1 & CBL has improved my learning skills & $47 \%$ & $20 \%$ & $10 \%$ & $16 \%$ & $7 \%$ \\
\hline 2 & CBL has facilitated my independent learning abilities & $55 \%$ & $24 \%$ & $11 \%$ & $10 \%$ & - \\
\hline 3 & CBL has enhanced my communication skills & $34 \%$ & $42 \%$ & $10 \%$ & $10 \%$ & $4 \%$ \\
\hline 4 & CBL has increased my analytical skills & $22 \%$ & $51 \%$ & $7 \%$ & $10 \%$ & $10 \%$ \\
\hline 5 & Learning objectives were achieved at the end of session & $32 \%$ & $34 \%$ & $22 \%$ & $12 \%$ & - \\
\hline 6 & CBL has helped me clearing the basic concepts & $44 \%$ & $38 \%$ & $10 \%$ & $8 \%$ & - \\
\hline 7 & CBL has helped me retaining relevant information & $28 \%$ & $47 \%$ & $15 \%$ & $6 \%$ & $4 \%$ \\
\hline 8 & CBL has worked as an effective learning tool for me & $66 \%$ & $30 \%$ & $4 \%$ & - & - \\
\hline
\end{tabular}

Singh etal., concluded that CBL is a very good approach to initiate student centred learning. This also helps students to understand practical application of the theory taught to them. We agree with the previous studies as most of our students provided positive opinion on CBL.

\section{CONCLUSION}

We recommend including CBL as a part and parcel of medical microbiology curriculum for better understanding of subject and for practical application.

Limitation Major limitation of our study was low sample size.

\section{Conflicts of interest Nil}

\section{REFERENCES}

1. Sprawls P. Evolving models for medical physics education and training: a global perspective. Biomed Imaging intervention J. 2008;4:e16.
2. Thistlethwaite JE, Davies D, Ekeocha S, Kidd JM, MacDougall C, Matthews P, Purkis J, Clay D. The effectiveness of case-based learning in health professional education. A BEME systematic review: BEME Guide No. 23. Med Teach. 2012;34(6):e421-44. doi: 10.3109/0142159X.2012.680939.

3. Suvarna Sande Tathe, A. L. Singh. case based lectures versus conventional lectures for teaching medical microbiology to undergraduate students. IJCCR. 2014; 6(4):36-41.

4. Farrukh Majeed. Effectiveness of case-based teaching of physiology for nursing students. Journal of Taibah University Medical Sciences. 2014; 9(4):289-292.

5. Praveen R Singh, Raksha Bhatt. Introduction of case based learning for teaching anatomy in a conventional medical school. J. Anat. Soc. India. 2011; 60(2) 232235. 